\title{
Spatial Perception of Urban Forests by Citizens Based on Semantic Differences and Cognitive Maps
}

\author{
Zheng Zhao ${ }^{1}$, Jie Ren ${ }^{2}$ and Yali Wen ${ }^{2, *}$ \\ 1 College of Tourism, Shanghai Normal University, Shanghai 200234, China; zzshnu@shnu.edu.cn \\ 2 School of Economics and Management, Beijing Forestry University, Beijing 100083, China; \\ 18935865666@163.com \\ * Correspondence: wenyali2003@163.com; Tel.: +86-10-62338455
}

Received: 15 November 2019; Accepted: 2 January 2020; Published: 4 January 2020

\begin{abstract}
Urban forests are more about people than trees. The positivist approach faces many obstacles in analyzing current urban forest-related issues; thus, this study adopted semantic differences and cognitive map approaches to evaluate the subjective preferences of citizens based on their spatial behavior. From December 2015 to November 2017, a three-year continuous public questionnaire was administered to a total of 450 citizens. Typical forest parks, suburban parks, and urban parks in Beijing were selected as research sites, and were analyzed respectively. This study comprehensively evaluated the perception characteristics and differences in the spatial images of urban forests by citizens in relation to different location conditions. Because these characteristics varied across individuals, the spatial cognition and familiarity of citizens with different types of urban forests were analyzed and compared. The perception of spatial images by citizens of different types of urban forests noticeably varied with respect to color and psychology. The perception of spatial images significantly varied with respect to gender, educational background, and income level, with individual characteristics being most closely related to the perception elements of urban forests in terms of space, color, style, and environment. Comparison of cognitive maps demonstrated clear differences in how citizens selected different types of urban forests. These differences were reflected in six types of cognitive maps and six familiar elements in the cognitive maps drawn by citizens.
\end{abstract}

Keywords: urban forest; citizens; semantic difference method; cognitive map; Beijing

\section{Introduction}

In the last 40 years of reform and opening up, along with the rapid development of urban areas, China's urban ecological environment has become increasingly prominent. Consequently, the requirements of citizens for urban living environments are constantly growing. Urban forests represent the main component of urban ecosystems, in addition to being important for maintaining urban ecological security. Urban forests are fundamental in the construction of urban ecological civilization. With the continued development of the economy and society, the Chinese government has also attached great importance towards improving the level of urban forest construction. Consequently, urban forest construction has become a key goal of urban development in China. Beijing is the capital of China, and is an international metropolis that has been subject to rapid development in recent years. The Beijing municipal government places strong emphasis on protecting the city's ecological environment. In particular, within the context of constructing a more ecologically oriented civilization, urban forests serve as a bridge for the harmonious coexistence of humans and nature. As a result, the government identifies new requirements for the construction of urban forests, along with injecting new impetus for developing and improving urban forests. 
The continued urbanization of China has generated problems to the urban ecological environment, in parallel to improved citizen awareness of the ecological environment. Serious environmental pollution problems that have attracted the attention of all of society, include smog and haze in big cities. Citizens in Beijing have realized that environmental problems are related to their lifestyle and interests, and that it is imperative to resolve these problems to improve the quality of life. Furthermore, as the main body of urban ecosystems, urban forests provide ecosystem services, i.e., they supply urban environmental public goods. However, rapid urbanization generates environmental pollution, traffic congestion, the reconstruction of infrastructure, and other problems that weaken the functioning of urban forest. These issues, in turn, negatively impact the healthy development of cities, and reduce the quality of life for urban citizens. Therefore, under the new goal of people-oriented modern urban development, urban forests in Beijing are now considered to be related to the well-being of individual citizens and the whole process of urbanization.

Urban forests have become an important means of improving the urban ecological environment and facilitating the sustainable development of cities. The role of urban forests must reflect the value attributes of their beneficiaries, namely, citizens. Therefore, more emphasis should be placed on the social attributes of urban forests. This can be achieved by using the characteristics of individual citizens to identify and distinguish their requirements. With increasing awareness of the importance for environmental protection in contemporary society, people's understanding of the value of urban forests has gradually grown. As a result, research on how urban forests, urban forestry, and people are interrelated, as well as associated impacts, has been emerging [1,2]. Previous studies demonstrated that the recognition, support, and positive feedback of citizens guarantee urban forest construction. In contrast, a single approach to environmental protection that is dominated by the government and does not attach importance to public opinion and behavior, fosters a negative attitude of public participation. Consequently, this approach is not conducive to the development of urban forests [3-5]. Therefore, improving the utilization of urban forest is expected to improve the functional level of urban forests, and reduce the possibility of problems emerging in the process of urban forest development [6]. In particular, urban forests are important for the development and construction of modern metropolises, such as Beijing, requiring both research and management focus.

Urban forests greatly improve the quality of life of citizens. In particular, different types of urban forests, improve the health of citizens and the level of environmental education, as well as providing space for recreation and entertainment [7-9]. There are many types of modern urban forests; however, all types represent a combination of natural and artificial resources. The different forms of urban forests have been studied based on their spatial layout, overall structure, multi-functional objectives, and ecological network [10,11]. For example, urban forests located in suburbs and mountainous areas are mostly used to construct and manage urban forest ecosystems. Over the years, these forests have contributed towards maintaining urban ecology, improving community environments, and ensuring the physical and mental health of citizens. The natural environment of urban forests can help citizens better recuperate and relieve pressure [12-14]. However, the city itself has social and economic functions and attributes. Placing greater focus on increasing vegetation coverage at the expense of the overall function of urban forests is not conducive to the overall development of a city [15]. Therefore, although the capacity of ecological services of parks and green spaces within a city is generally not high, this component tends to be favored by some citizens [16]. Accordingly, the perceptions and feedback of citizens on urban forests represent important components for developing and improving urban forests. Important parameters of citizens include their individual characteristics, the degree of citizenship, and the degree of familiarity with urban forests [1,4,17]. Individual citizens are expected to perceive different types of urban forests differently depending on variation in space-time conditions, which then affects their behavior [18]. Because different types of urban forests play different roles, the perceptions of citizens are also expected to vary. Therefore, it is necessary to classify and discuss these perceptions using a specific analytical process. 
Beijing is the capital of China, representing a typical metropolis of the region. Therefore, it is ideal for conducting an empirical analysis at the citizen level. Macroscopically speaking, China's cities and urban forests tend to have certain idiosyncrasies. For instance, large cities tend to have enormous population, resource, and environmental pressures, with the construction of corresponding urban forests often being constrained by the existing socio-economic conditions. In parallel, urban residents have weak perceptions of urban forests in China, with the importance of urban forests not being evident in the current overall process of urban development. Yet, people's perceptions of urban forests have gradually expanded from traditional aesthetic and practical functions to psychological and emotional satisfaction. Therefore, simplified mathematical and statistical models based on the objective characteristics of citizens and urban forests are not sufficient to explain the complexity of urban forests and the initiatives of citizens for using them. In other words, the positivist approach faces many obstacles when analyzing issues related to current urban forests. Studies have begun acknowledging that the subjectivity and objectivity of urban forests are equally important. The research object of urban forests has now expanded to the "subjective world" of urban forests, including "perceptual space" and "image maps" [19]. As a result, the semantic difference method has been used in many fields of research, and is often used in combination with other statistical methods. Starting from the function, composition, and design of urban forests, the perceptions of citizens have been extensively discussed, especially in studies of urban forests, urban parks, and community greening [1,18,20-26]. Similarly, based on mature cognitive maps and spatial cognitive theory, the cognitive map method has been widely used in decision-making processes associated with spatial behavior and urban planning, expanding the research scope of the subjective will of micro-subjects [27-29]. These concepts and methods provide the basis on which the current study was developed.

The current study aimed to deconstruct how citizens perceive urban forests in Beijing, China, based on their spatial scope, image elements, and image subject attributes. The semantic difference method and cognitive map method were used to conduct a comprehensive analysis of the perception characteristics and differences to urban forest spatial images of citizens in three types of urban forest forms (forest parks, suburban parks, and urban parks), with different location conditions and individual characteristics. The spatial awareness and familiarity of citizens of different types of urban forests were also compared and analyzed. The results of this study are expected to help promote the function of urban forests and their sustainable development in the future, providing a reference for the planning and management of relevant departments of urban forests in major cities, facilitating the rational and humanized urban forest construction.

\section{Materials and Survey Design}

\subsection{Selection of Study Areas}

At present, debate exists over how to categorize urban forests in studies globally; however, the basic perspective is the same, that is, urban forests are areas where forests, trees, and other plants grow in an urban area, supporting wildlife and the related facilities belong to a given category of urban forest. Based on the results of existing studies and relevant norms, this study identified specific survey sites as typical urban forest areas in Beijing, including forest parks, suburban parks, and urban parks $[22,30]$. Because areas with high vegetation coverage in Beijing are mostly located in the west and northwest parts of the city, the northwest section of Beijing was selected as the research area, covering most of the Haidian District, Xicheng District, and parts of the Chaoyang and Shijingshan Districts. The research area includes three typical urban forests: A forest park, a suburban park, and an urban park. The area also reflected the spatial transition of these three urban forest forms (Figure 1).

(1) Forest parks mainly refer to urban forest areas located in suburban areas with low population density and high forest coverage. Thus, this study selected Xiangshan Park as the representative forest park for investigation. The park is located in the middle of Haidian District, Beijing, outside the Northwest Fifth Ring Road. From a topographic perspective, the park is located at the eastern 
foot of the Xishan Mountains in Beijing. Xiangshan Park was founded in 1186, and has a history of more than 900 years. It is an ancient royal garden with mountain forest characteristics. In ancient times, the emperor would visit the park to hunt in summer and fall. Xiangshan Park is a national and tourist attraction because it contains famous tourist attractions, including Xiangshan Temple, Hongguang Temple, and Shuangqing Villa. It is also one of the best parks in Beijing. The park contains more than 260,000 trees, with 98\% forest coverage. More than 5800 of the trees are ancient, accounting for a quarter of all ancient trees in Beijing. Xiangshan Park is also famous for its red leaves, making it one of the 16 scenic spots in Beijing. Citizens mainly use Xiangshan Park because they only need to travel short distances, as well as for camping and other recreational activities. Yet, the frequency and degree of utilization of this park is lower than other forms of urban forests near the city center.

(2) Suburban parks mainly refer to urban forest areas located at the junction of forest parks and urban areas. Citizens use such urban forests more than forest parks. This study selected the Summer Palace as the representative of suburban park for investigation. The Summer Palace is located between the 4th Ring Road and the 5th Ring Road in the northwest suburb of Beijing, and is $15 \mathrm{~km}$ from the urban area. It is a large-scale, landscaped garden built by the design method of gardens in southern China. It is also the most complete royal garden in China. The Summer Palace encompasses more than 3000 palace garden buildings in various forms, including administration, life, and tourism. Today, it is an important place for citizens to spend the summer at leisure. The Summer Palace is one of the four famous gardens in China, and was listed as a world heritage site in November 1998. The current study did not select suburban parks following the method of Hansmann et al. (2007) because the urbanization of Beijing has accelerated recently, with urban forests being used as land for construction, to some extent [22]. The Summer Palace is relatively close to the core of the city, with convenient traffic conditions. However, the population of Beijing has expanded rapidly in recent years, with the population between the 4th and 5th Ring Roads rapidly increasing, thus increasing the frequency and degree of utilization of suburban parks in this region.

(3) Urban parks refer to public parks located in urban areas. Thus, this study selected Yuyuantan Park as the representative urban park for investigation. Urban parks have lower natural resources and forest coverage than other forms of urban forests; however, because they are located in densely populated areas in the city center, urban parks are the most utilized form of park by citizens. Yuyuantan Park has a cherry blossom garden and other characteristic landscapes, as well as amusement parks, boat docks, forest cabins, water parks, and other amusement facilities, plus various kinds of perfect service equipment. The most important role of urban parks is to provide citizens with areas for daily exercise, recreation, and entertainment space. These parks also help regulate the urban microclimate. The construction of urban parks is often closely related to the degree of urbanization. Consequently, the value of these parks is reflected by their actual service functions, rather than historical relics and cultural accumulation.

To ensure that the answers of respondents were representative, we recruited respondents who have lived in the vicinity of urban forest area for some time. The survey sites selected in this study were specific urban forest areas, and each typical survey site represented a clear example of its urban forest type. Of note, citizens choose the urban forests that they frequent based on their preferences, time, and other factors. However, respondents tend to choose urban forests located closest to their place of residence or work for activities. 


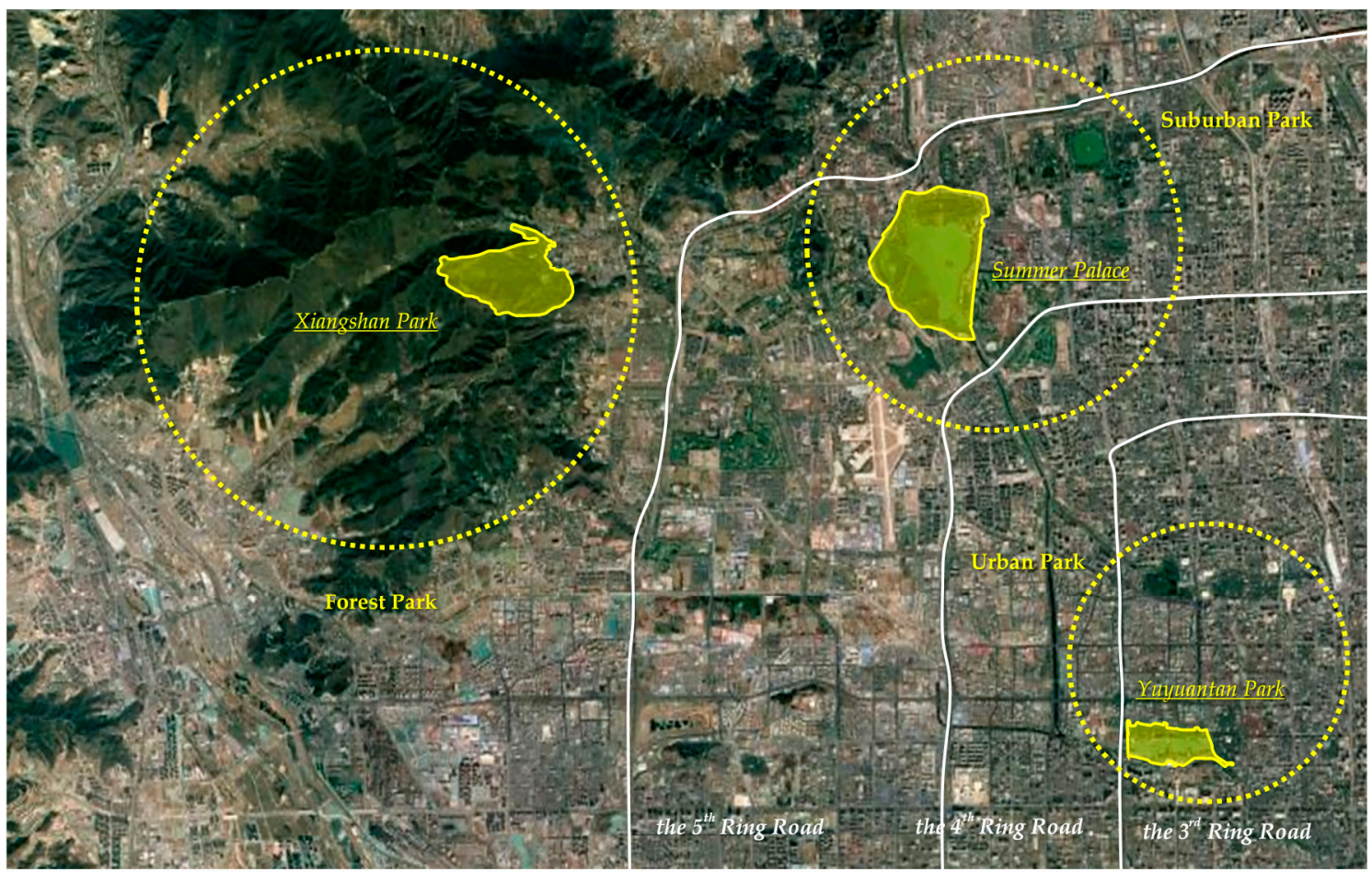

Figure 1. Research area of this study.

\subsection{Questionnaire Design}

The questionnaire was designed in three steps. First, the questionnaire framework was established. A preliminary draft of the questionnaire was prepared based on the analysis of existing literature, expert interviews, and group discussions. The content of the questionnaire was developed in order to provide a concentrated reflection of the core issues and basic assumptions of the study. Second, the questionnaire was tested and revised. Options or questions with low reliability or validity were detected and removed based on pre-survey activities to improve the overall quality. Third, the questionnaire was modified, improved and finalized. Using the questionnaire, data from Xiangshan Park, Summer Palace, and Yuyuantan Park in Beijing were collected over three consecutive years.

The core principles of this study are efficiency and comprehensiveness. These principles made the questionnaire as concise and clear as possible to improve the responsiveness of citizens and the utility and accuracy of the obtained data. Existing publications were used to enhance the responsiveness of citizens to questionnaires [31,32]. The average completion time for a comprehensive and qualified citizen questionnaire is about $35-45 \mathrm{~min}$.

\subsection{Data Collection}

Based on selected research areas, questionnaires, and corresponding survey methods, field surveys were conducted in December 2015, July 2016, December 2016, January 2017, and November 2017. Investigators were all graduate students with professional learning background and field investigation experience. Investigators underwent systematic training on research methods and data collection before carrying out their work. Overall, 480 questionnaires were completed, of which 450 questionnaires were validated. The overall effective response rate was $93.75 \%$. The descriptive statistics of samples are shown in Table 1. 
Table 1. Descriptive statistics of samples (\%).

\begin{tabular}{|c|c|c|c|c|c|c|c|}
\hline Variable & $\begin{array}{l}\text { Forest } \\
\text { Park }\end{array}$ & $\begin{array}{c}\text { Suburban } \\
\text { Park }\end{array}$ & $\begin{array}{c}\text { Urban } \\
\text { Park }\end{array}$ & Variable & $\begin{array}{l}\text { Forest } \\
\text { Park }\end{array}$ & $\begin{array}{c}\text { Suburban } \\
\text { Park }\end{array}$ & $\begin{array}{c}\text { Urban } \\
\text { Park }\end{array}$ \\
\hline$\left(X_{1}\right)$ Gender & \multicolumn{7}{|c|}{$\left(\mathrm{X}_{8}\right)$ Health status } \\
\hline Men & 42.67 & 48.67 & 51.33 & Very good & 2.00 & 1.33 & 0.67 \\
\hline$\left(X_{2}\right)$ Age & & & & Commonly & 40.67 & 54.00 & 45.33 \\
\hline Age 17 and under & 0.67 & 3.33 & 0.67 & Relatively poor & 24.67 & 24.67 & 26.67 \\
\hline $18-29$ years old & 59.33 & 34.00 & 34.00 & Very poor & 5.33 & 1.33 & 2.67 \\
\hline 50-59 years old & 6.00 & 6.67 & 15.33 & No & 73.33 & 58.00 & 48.00 \\
\hline Age 60 and over & 3.33 & 6.00 & 12.67 & \multicolumn{4}{|l|}{$\left(X_{10}\right)$ Residence in Beijing } \\
\hline$\left(X_{3}\right)$ Education status & & & & Within 1 years & 16.67 & 8.67 & 11.33 \\
\hline Primary school and below & 2.67 & 3.33 & 2.67 & 1 to 5 years & 40.67 & 25.33 & 24.67 \\
\hline Junior middle school & 6.00 & 14.00 & 8.00 & 5 to 10 years & 14.67 & 16.67 & 9.33 \\
\hline Unmarried & 59.33 & 42.00 & 34.00 & 3-6 months & 6.00 & 2.67 & 6.67 \\
\hline Married & 40.67 & 58.00 & 66.00 & 6-9 months & 16.67 & 19.33 & 12.67 \\
\hline$\left(X_{5}\right)$ Family size & & & & More than 9 months & 65.33 & 74.67 & 75.33 \\
\hline 1 person & 7.33 & 10.00 & 8.67 & \multicolumn{3}{|c|}{$\left(X_{12}\right)$ Per capita monthly income } & \\
\hline 2 persons & 14.67 & 13.33 & 12.00 & $¥ 4000$ and below & 39.33 & 24.67 & 30.00 \\
\hline 3 persons & 34.00 & 32.67 & 40.00 & $¥ 4001-¥ 8000$ & 27.33 & 26.67 & 26.67 \\
\hline 4 persons & 24.67 & 28.00 & 26.67 & $¥ 8001-¥ 12,000$ & 14.00 & 22.67 & 20.67 \\
\hline 5 persons or more & 19.33 & 16.00 & 12.67 & $¥ 12,001-¥ 16,000$ & 9.33 & 8.00 & 9.33 \\
\hline \multicolumn{2}{|c|}{$\left(\mathrm{X}_{6}\right)$ Number of elderly people } & & & $¥ 16,001-¥ 20,000$ & 5.33 & 9.33 & 6.00 \\
\hline 1 person or less & 50.67 & 50.67 & 58.00 & More than 20,000 & 4.67 & 8.67 & 7.33 \\
\hline 2 persons & 31.33 & 36.67 & 28.67 & \multicolumn{2}{|l|}{$\left(X_{13}\right)$ Residential area } & & \\
\hline 3 persons or more & 18.00 & 12.67 & 13.33 & Within 2nd Ring Rd & 4.00 & 6.00 & 14.67 \\
\hline
\end{tabular}

Regarding respondent characteristics, the proportion of women was slightly higher than that of men. About $80 \%$ of respondents were under 40 years old, and the citizens sampled in urban parks were relatively older. More than $80 \%$ of respondents had high school or higher education backgrounds. The proportion of unmarried citizens in forest parks was slightly higher than that in suburban parks and urban parks. The total family size of the respondents was more than three, of which the average number of elderly people was less than two, and the number of children was more than one. The health status of the respondents was uniformly distributed. The average monthly income of half of the respondents was below 8000 yuan. Fewer respondents has Beijing residence registration than those without it, and the number of people who have had lived in Beijing for 1-5 years and the number of people who have lived in Beijing for more than 15 years is large. Most citizens live in Beijing for six months every year. More than half of urban park respondents lived between the Second and Fifth Ring Roads, which was consistent with the expected number and population density of citizens in the core urban area of Beijing (being relatively larger). This phenomenon also explained why most Beijing citizens who visit urban parks live in this area, that is to say, the frequency of these citizens visiting urban parks is higher than that of the other two types of urban forests.

\section{Methods and Model Design}

\subsection{Research Methods}

Surveys of the behavioral preferences of citizens represent an important tool for studying urban spatial perceptions [33]. Semantic Differential (SD) is a psychological research method proposed by Osgood (1957) [34]. This method is easy to implement, and can be used for the objective quantitative analysis of research objects. In fact, the SD method is used in many fields of research globally. It is 
often used in combination with other statistical methods [21]. The macro level includes studying urban space as a whole, and the micro level includes studying architectural space and street space $[35,36]$. The SD method holds that human beings have broad and common emotional meanings to concepts or vocabulary, and that there is no major variation due to cultural and linguistic differences. Therefore, it is reasonable and effective to ask respondents directly about the meaning of a concept.

Parallel to the SD method, this study used cognitive map analysis to evaluate the spatial perception image of citizens of Beijing urban forests. The concept of the cognitive map was first proposed by Tolman (1948) in the process of the "The Rat Maze Walking" experiment, and entered China in the 1980s [37]. Gao (1991) laid the foundation for studying cognitive maps and spatial cognitive theory in China [38]. Since then, research related to cognitive maps has expanded. Some studies have combined cognitive map method with the closed questionnaire survey method [39-41]. Through a large number of empirical studies, five image elements of cognitive maps have been established; namely landmarks, roads, nodes, regions, and boundaries [42-46]. Accordingly, hand-drawn cognitive maps are considered to be direct graphical methods. Respondents are requested to attempt to draw information on the shape, location, and structure layout of objects [47]. This study applies image theory to the study of urban forests, that is, citizens have different emotional memories and subjective impressions of urban forests, and the objective image of urban forests can be embodied by the image perceptions of citizens. Therefore, in the current survey, the same citizens used for the SD method also participated in the cognitive map method, and were asked to prepare a hand-drawn map. In addition, considering the difficulties in obtaining information from hand-drawn cognitive maps, this study divided citizens into two types: (1) Citizens with a deep perception of the spatial image of urban forests who were requested to draw a hand-drawn cognitive map; and (2) citizens with a vague perception of the spatial image of urban forests who completed hand-drawn map, and were asked by the investigator to select the most familiar elements on the map. The purpose of these two surveys was to obtain information on how familiar the spatial image perceptions of citizens were for different types of urban forests. Frequency distribution statistics and comparative analysis were conducted on this information.

\subsection{Description of Variables}

The perceptions, utilization, and preference of urban forests by respondents tend to be influenced by individual functional and structural variables (age, marriage, education, etc.), social and cultural political variables (income, household registration, etc.), and spatial variables (residence time, location, distance, etc.). Thus, 12 pairs of adjective combinations were selected to describe the characteristics of urban forests with opposite meanings. A semantic differential scale on the evaluation of urban forest perception was constructed to reflect the psychological feelings of respondents about urban forests. Six evaluation elements and 12 evaluation items were used, each of which corresponded to a pair of adjective combinations, namely the evaluation factors of this study (Table 2). The evaluation items (categories) provide a clear expression of evaluation elements (variables), which were selected by combining the characteristics of urban forests in Beijing and the cognitive ability of Beijing citizens.

Based on the evaluation factors listed in Table 2, the evaluation scale was classified into five levels, with five interval values being selected between each adjective combination. These intervals were symmetrical, with 0 as the midpoint. The interval values were $-2,-1,0,1$, and 2 from left to right, and were used as the options for citizens to evaluate scoring. The higher the score of each evaluation item, the more inclined the evaluation factor adjective was to the right, while the lower the score, the more inclined the evaluation factor adjective was to the left. 
Table 2. Scale on SD semantic differences for spatial image perception of urban forests in Beijing.

\begin{tabular}{ccccc}
\hline Category & Symbol & Variable & Index & Definition \\
\hline \multirow{2}{*}{ Space } & $\mathrm{M}_{1}$ & Sense of space & Enclosed-Wide & Spatial looseness and intensity of urban forest \\
& $\mathrm{M}_{2}$ & Sense of order & Disordered-Ordered & Orderliness and orderliness of urban forests \\
Distance & $\mathrm{M}_{3}$ & From urban areas & Far-Close & Distance between urban forests and urban areas \\
& $\mathrm{M}_{4}$ & From rural areas & Far-Close & Distance between urban forest and rural areas \\
Color & $\mathrm{M}_{5}$ & Hue & Dark-Clear & Brightness and contrast of urban forest \\
& $\mathrm{M}_{6}$ & Color temperature & Cold-Warm & Overall hues of urban forests \\
Style & $\mathrm{M}_{7}$ & Natural form & Light-Heavy & Natural form degree of urban forest \\
& $\mathrm{M}_{8}$ & Artificial trace & Light-Heavy & Artificial trace degree of urban forest \\
\multirow{2}{*}{ Psychology } & $\mathrm{M}_{9}$ & Sense of belonging & Unfamiliar-Familiar & The sense of belonging and familiarity of urban forests \\
& $\mathrm{M}_{10}$ & Sense of security & Danger-Safe & Public security management of urban forests \\
Environment & $\mathrm{M}_{11}$ & Greening coverage & Low-High & Greening coverage of urban forests \\
& $\mathrm{M}_{12}$ & Greening facilities & Imperfect-Perfect & Improvement of greening facilities in urban forests \\
\hline
\end{tabular}

\section{Results}

\subsection{Regional Differences of Citizens' Perceptions}

In general, the distribution of the spatial perception of different urban forests was highly uniform and similar, but with some differences. Specific differences are delineated from the SD scores of each evaluation project, with the corresponding SD evaluation curve being obtained from the data statistics of each factor after being assigned (Figure 2). SD scores intuitively show the trend difference between different urban forest types, that is, differences in the perception evaluations of citizens, thus reflecting the characteristics, advantages, and disadvantages of different types of urban forests. In general, the advantages and disadvantages of different urban forest types are closely related to their geographical location and corresponding location conditions. They differ greatly in spatial image perceptions of color (color temperature and hue) and psychology (sense of belonging and security), with relatively moderate differences for other aspects. Three key observations were made based on the different types of urban forests. The advantages of forest parks were warm color temperature and light artificial traces, and their disadvantages were a lower sense of belonging and lack of security. The advantages of suburban parks were clear colors and higher sense of security, as well as some advantages of both forest parks and urban parks, including appropriate location, clear color, and warm color temperature. The advantages of urban parks were mainly embodied by their orderly layout and high sense of security, while the disadvantages were weak natural forms, low greening coverage, and relatively enclosed sense of space.

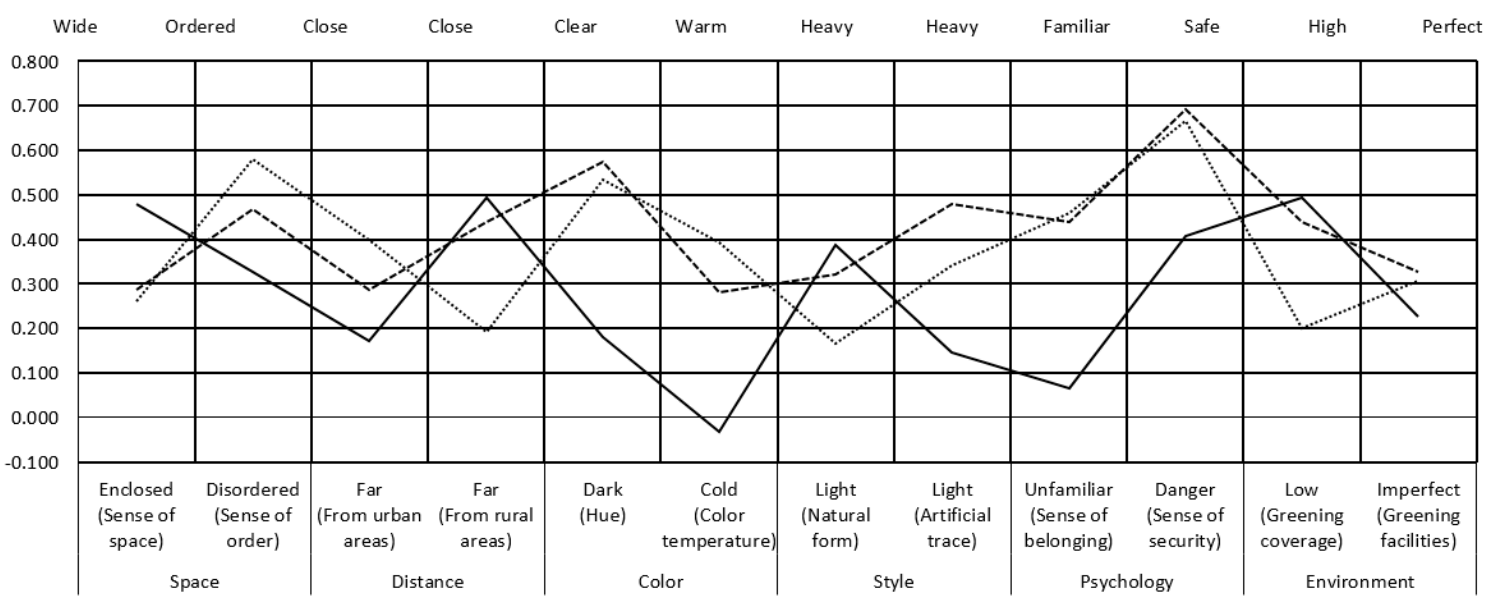

Figure 2. The SD evaluation curve of this study. 
To reflect the perceptions differences of citizens on various evaluation projects, this study conducted an independent sample test on perception differences across the three urban forest types (Table 3). Urban forests had clear differences in how citizens perceive vision, psychology, and environment. However, differences in style and space were not obvious. Significant differences were perceived in the hue $\left(\mathrm{M}_{5}\right)$, sense of belonging $\left(\mathrm{M}_{9}\right)$, and greening facilities $\left(\mathrm{M}_{12}\right)$ between forest parks and suburban parks, as well as a sense of order $\left(\mathrm{M}_{2}\right)$ and natural form $\left(\mathrm{M}_{7}\right)$. There were significant differences in how natural forms were perceived between suburban parks and urban parks, as well as in greening facilities $\left(\mathrm{M}_{12}\right)$ and artificial traces $\left(\mathrm{M}_{8}\right)$. In contrast, differences in how citizens perceive forest parks and urban parks were not significant.

Table 3. Independent samples test of spatial image perception of urban forests in Beijing.

\begin{tabular}{|c|c|c|c|c|c|c|c|c|}
\hline \multirow[t]{2}{*}{ Category } & \multirow[t]{2}{*}{ Symbol } & \multirow[t]{2}{*}{ Variable } & \multicolumn{2}{|c|}{$\begin{array}{l}\text { Forest Park and } \\
\text { Suburban Park }\end{array}$} & \multicolumn{2}{|c|}{$\begin{array}{c}\text { Forest Park and } \\
\text { Urban Park }\end{array}$} & \multicolumn{2}{|c|}{$\begin{array}{c}\text { Suburban Park and } \\
\text { Urban Park }\end{array}$} \\
\hline & & & $\mathbf{F}$ & Sig. & $\mathbf{F}$ & Sig. & $\mathbf{F}$ & Sig. \\
\hline \multirow{2}{*}{ Space } & $\mathrm{M}_{1}$ & Sense of space & 0.983 & 0.322 & 2.141 & 0.144 & 0.281 & 0.597 \\
\hline & $\mathrm{M}_{2}$ & Sense of order & $3.612 *$ & 0.058 & 0.511 & 0.475 & 1.581 & 0.210 \\
\hline \multirow{2}{*}{ Distance } & $\mathrm{M}_{3}$ & From urban areas & 1.441 & 0.231 & 0.596 & 0.441 & 0.243 & 0.622 \\
\hline & $\mathrm{M}_{4}$ & From rural areas & 1.078 & 0.300 & 0.052 & 0.820 & 1.306 & 0.254 \\
\hline \multirow{2}{*}{ Color } & $\mathrm{M}_{5}$ & Hue & 1.138 & 0.287 & 0.310 & 0.578 & 0.344 & 0.558 \\
\hline & $\mathrm{M}_{6}$ & Color temperature & $4.220 * *$ & 0.041 & 0.309 & 0.579 & $3.427^{*}$ & 0.065 \\
\hline \multirow{2}{*}{ Style } & $\mathrm{M}_{7}$ & Natural form & $3.855^{*}$ & 0.051 & 0.940 & 0.333 & $7.457^{* * *}$ & 0.007 \\
\hline & $\mathrm{M}_{8}$ & Artificial trace & 2.316 & 0.129 & 0.001 & 0.973 & $2.979 *$ & 0.085 \\
\hline \multirow{2}{*}{ Psychology } & $\mathrm{M}_{9}$ & Sense of belonging & $5.791 * *$ & 0.017 & 2.557 & 0.111 & 0.905 & 0.342 \\
\hline & $\mathrm{M}_{10}$ & Sense of security & 0.221 & 0.639 & 0.135 & 0.714 & 0.768 & 0.381 \\
\hline \multirow{2}{*}{ Environment } & $\mathrm{M}_{11}$ & Greening coverage & 0.815 & 0.367 & 1.334 & 0.249 & 0.094 & 0.759 \\
\hline & $\mathrm{M}_{12}$ & Greening facilities & $5.242 * *$ & 0.023 & 0.002 & 0.962 & $5.538 * *$ & 0.019 \\
\hline
\end{tabular}

Note: ${ }^{* * *},{ }^{* *}$ and ${ }^{*}$ represent significant levels of $1 \%, 5 \%$ and $10 \%$ respectively.

\subsection{Differences in the Perceptions of Individual Citizens}

Previous studies showed that there is a certain correlation between how citizens perceive urban forests and their individual characteristics [35]. In this study, the correlation coefficient tables between 12 categories of citizen perceptions and 13 individual characteristics were evaluated (Table 4). How citizens perceived the spatial images of urban forests was correlated with their individual characteristics. Correspondingly, there was a certain difference between how citizens perceived spatial images and their individual characteristics, that is, some characteristics of urban forests could not be perceived by citizens. 
Table 4. Pearson's relevance test between the spatial image perception of citizens and their individual characteristics.

\begin{tabular}{|c|c|c|c|c|c|c|c|c|c|c|c|c|c|}
\hline Characteristics & Variable & $\mathbf{M}_{1}$ & $\mathbf{M}_{2}$ & $\mathbf{M}_{3}$ & $\mathbf{M}_{4}$ & $\mathbf{M}_{5}$ & $\mathbf{M}_{6}$ & $\mathbf{M}_{7}$ & $\mathbf{M}_{8}$ & $\mathbf{M}_{9}$ & $\mathbf{M}_{10}$ & $\mathbf{M}_{11}$ & $\mathbf{M}_{12}$ \\
\hline$x_{1}$ & & 0.005 & -0.059 & -0.011 & -0.056 & $-0.077^{*}$ & -0.052 & -0.083 * & -0.053 & -0.079 * & 0.026 & 0.048 & $-0.082 *$ \\
\hline$x_{2}$ & & -0.030 & $0.104^{* *}$ & 0.067 & -0.031 & 0.044 & $0.148^{* * *}$ & 0.033 & 0.053 & 0.032 & -0.001 & -0.024 & 0.052 \\
\hline$x_{3}$ & & -0.038 & $-0.151^{* * *}$ & 0.021 & -0.018 & $-0.169 * * *$ & -0.080 * & $-0.094^{* *}$ & -0.069 & -0.090 * & 0.025 & 0.011 & $-0.113^{* *}$ \\
\hline$X_{4}$ & & $-0.083^{*}$ & 0.045 & 0.077 * & -0.032 & 0.019 & $0.149 * * *$ & 0.026 & 0.033 & 0.037 & -0.002 & -0.023 & 0.032 \\
\hline$x_{5}$ & & 0.002 & 0.075 & -0.026 & 0.031 & 0.073 & -0.035 & 0.056 & 0.036 & -0.002 & $0.130^{* * *}$ & 0.009 & 0.016 \\
\hline$x_{6}$ & & 0.009 & -0.034 & 0.008 & 0.017 & -0.041 & 0.034 & -0.013 & -0.016 & 0.086 & -0.080 * & -0.044 & 0.014 \\
\hline$x_{7}$ & & -0.009 & 0.014 & 0.037 & 0.006 & 0.048 & 0.018 & $0.107^{* *}$ & $0.082 *$ & 0.015 & -0.038 & 0.034 & 0.043 \\
\hline$x_{8}$ & & 0.047 & 0.036 & 0.044 & -0.041 & 0.075 & 0.043 & 0.054 & 0.001 & 0.069 & 0.003 & -0.009 & $0.119^{* *}$ \\
\hline$x_{9}$ & & 0.060 & 0.009 & $-0.086^{*}$ & 0.021 & 0.032 & $-0.086^{*}$ & 0.029 & 0.001 & -0.038 & 0.011 & 0.073 & 0.026 \\
\hline$x_{10}$ & & -0.046 & 0.013 & 0.078 * & -0.070 & 0.050 & $0.115^{* *}$ & 0.020 & 0.039 & 0.075 & 0.000 & -0.041 & 0.000 \\
\hline$x_{11}$ & & 0.066 & 0.003 & 0.031 & -0.032 & -0.024 & 0.022 & -0.015 & 0.023 & -0.012 & 0.017 & -0.040 & -0.084 * \\
\hline$x_{12}$ & & -0.019 & $-0.117^{* *}$ & -0.078 * & -0.031 & $-0.113^{* *}$ & -0.025 & $-0.094^{* *}$ & -0.060 & -0.029 & -0.011 & -0.074 & -0.040 \\
\hline $\mathrm{X}_{13}$ & & 0.032 & -0.050 & -0.032 & $0.095^{* *}$ & -0.056 & $-0.124^{* * *}$ & 0.047 & -0.002 & -0.072 & -0.059 & -0.010 & -0.040 \\
\hline
\end{tabular}


Based on the individual characteristics of citizens, factors such as gender $\left(\mathrm{X}_{1}\right)$, educational background $\left(X_{3}\right)$, and monthly income $\left(X_{12}\right)$ had the strongest correlation with their spatial image perception of urban forests. Therefore, when constructing Beijing's urban forests, the specific needs of men and women should be considered, as well as the corresponding needs of citizens of different educational and income levels. Based on how individual citizens perceived urban forest spatial images, citizen perceptions of space were strongly correlated with the distance between urban forest and urban area $\left(\mathrm{M}_{1}\right)$, color including color temperature $\left(\mathrm{M}_{6}\right)$, style including natural form $\left(\mathrm{M}_{7}\right)$, and environment including the construction of greening facilities $\left(\mathrm{M}_{12}\right)$. Thus, citizens perceived urban forest spatial images at an intuitive visual level. In parallel, citizens were strongly concerned about the construction of urban forest infrastructure, confirming that citizens have an increasing and objective demand for urban forests.

\subsection{Cognitive Maps Perceived by Citizens}

SD analysis was combined with a cognitive map method to compare and analyze the familiarity of how citizens perceive the spatial images of different urban forest types. Figure 3 presents example of hand-drawn cognitive maps. The familiarity of citizens in perceiving urban forest spatial images varied across individuals.
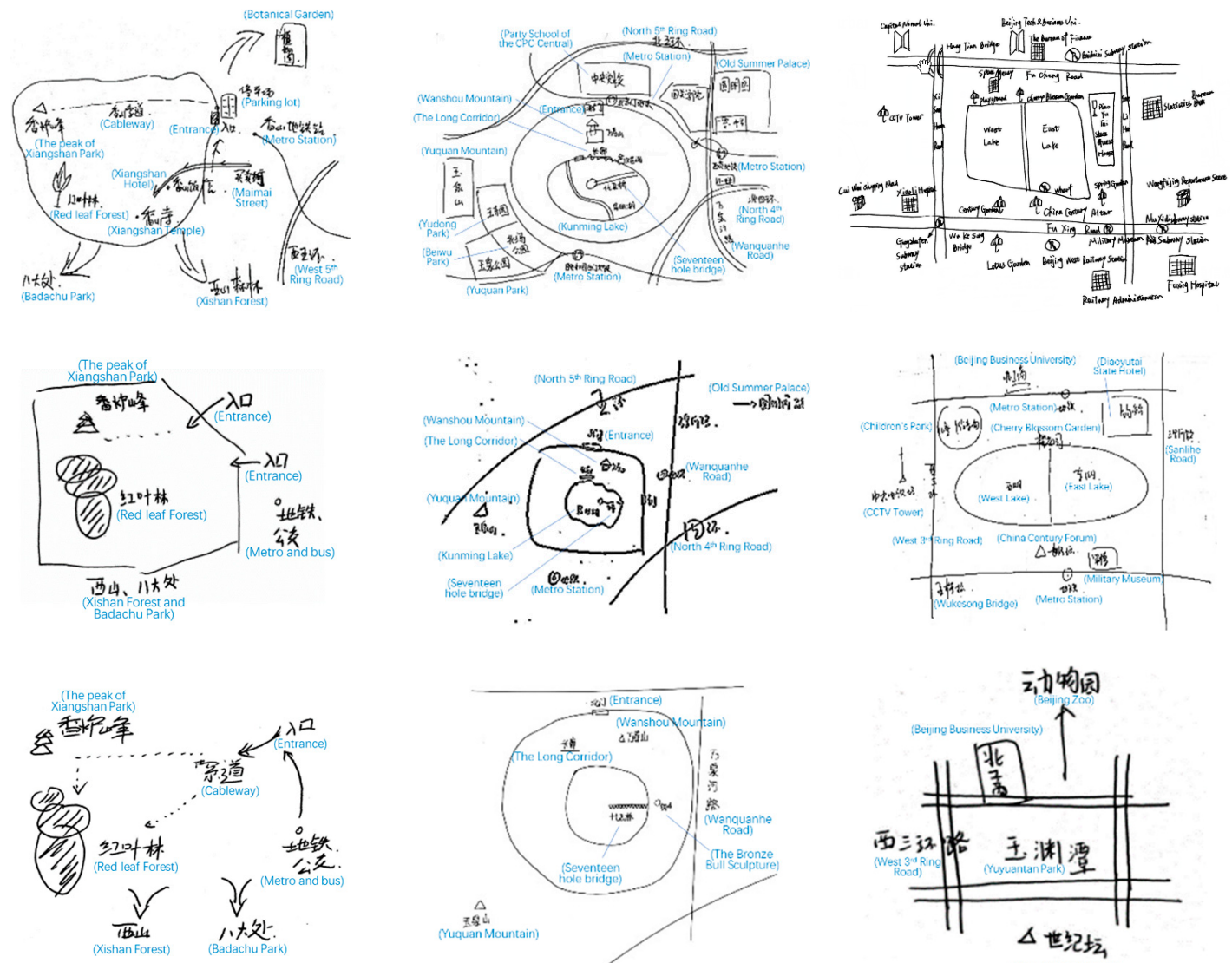

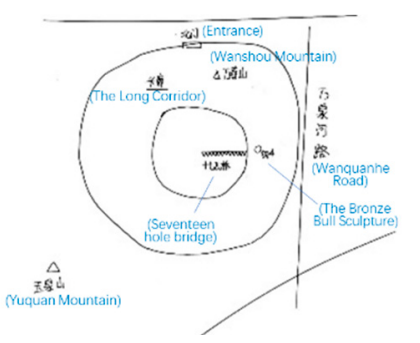

(Suburban Park)

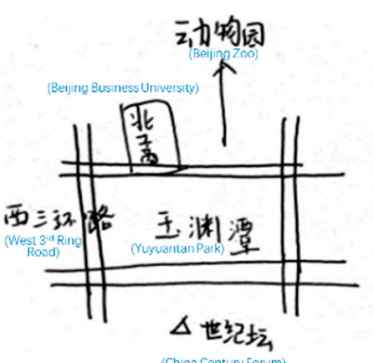

(Urban Park)

(Forest Park)

Figure 3. The example of hand-drawn cognitive maps of this study. 
Based on the classification criteria of cognitive maps proposed by Appleyard (1970), the cognitive maps obtained in this study were roughly divided into sequential cognitive maps (including linear, branch and chain cognitive maps), mainly with path elements, and spatial cognitive maps (including scattered, mosaic and connected cognitive maps), as well as regional elements [43]. A linear cognitive map represents a branch map that includes the main roads inside and around the urban forests of the current study, or a more detailed linear perception map. A branch cognitive map is a branch map that contains the elements of an urban forest that were considered impressive by the interviewees, and could connect the elements through the path. A chain cognitive map was based on the chain map around the main roads of the urban forest. A scattered cognitive map contained a combination of scenic spots or areas with specific impressions, which roughly reflected the perception of the spatial image of an urban forest. A mosaic cognitive map was a combination of different areas of urban forests in the memory of the respondents, so that it could be combined into the perception of the spatial image of an urban forest. Connected cognitive maps were the spatial segments of urban forests connected by the necessary traffic roads and facilities [48]. The cognitive maps obtained in this study are shown in Table 5, of which 53.13 were sequential cognitive maps and 46.88 were spatial cognitive maps.

Table 5. Statistics of the cognitive maps.

\begin{tabular}{|c|c|c|c|c|c|c|}
\hline \multirow[b]{2}{*}{ Index } & \multicolumn{3}{|c|}{ Sequential Cognitive Maps } & \multicolumn{3}{|c|}{ Spatial Cognitive Maps } \\
\hline & Linear & Branch & Chain & Scattered & Mosaic & Connected \\
\hline Quantity & 78 & 90 & 70 & 59 & 72 & 79 \\
\hline Proportion (\%) & $17.41 \%$ & $20.09 \%$ & $15.63 \%$ & $13.17 \%$ & $16.07 \%$ & $17.63 \%$ \\
\hline
\end{tabular}

The maximum likelihood method was used to classify the types of hand-drawn cognitive maps based on the individual characteristics of different citizens, and to estimate the degree and significance of their impact. A disordered multivariate logit model was constructed to calculate the types of cognitive maps and compare them. Disordered multiple choice models were used for the calculations because: (1) The six types of cognitive map are arranged disorderly, and the possibility of drawing a particular type of map is also disorderly for citizens; and (2) the function of the selection model used to calculate these problems is similar, but the multivariate Probit model is more complex, so the multivariate Logit model was used. Linear, branched, chain, scattered, mosaic, and connected cognitive maps were set up for Scheme 1 (P1), Scheme 2 (P2), Scheme 3 (P3), Scheme 4 (P4), Scheme 5 (P5), and Scheme 6 (P6), respectively. Schemes 1 and 5 were set as an experimental group and Scheme 6 was set as the reference group. Based on the Wald test results, the final results were obtained by eliminating the variables for which parameter estimates were zero (Table 6). 
Table 6. Results of maximum likelihood estimates for the MNL model.

\begin{tabular}{|c|c|c|c|c|c|c|c|c|c|c|c|}
\hline \multirow{2}{*}{ Index } & \multicolumn{2}{|c|}{ Scheme $1 \ln \left(\mathbf{P}_{1} / \mathbf{P}_{6}\right)$} & \multicolumn{2}{|c|}{ Scheme $2 \ln \left(\mathbf{P}_{2} / \mathbf{P}_{6}\right)$} & \multicolumn{2}{|c|}{ Scheme $3 \ln \left(P_{3} / P_{6}\right)$} & \multicolumn{2}{|c|}{ Scheme $4 \ln \left(\mathbf{P}_{4} / \mathbf{P}_{6}\right)$} & \multicolumn{2}{|c|}{ Scheme $5 \ln \left(\mathbf{P}_{5} / \mathbf{P}_{6}\right)$} & \multirow{2}{*}{$\begin{array}{c}\text { Type of } \\
\text { Cognitive Maps }\end{array}$} \\
\hline & B & $\operatorname{Exp}(B)$ & B & $\operatorname{Exp}(B)$ & B & $\operatorname{Exp}(B)$ & B & $\operatorname{Exp}(B)$ & B & $\operatorname{Exp}(B)$ & \\
\hline \multicolumn{12}{|l|}{ Age } \\
\hline $18-29$ & 0.31 & 1.37 & 0.99 & 2.68 & -0.20 & 0.82 & 1.38 & 3.96 & 1.94 * & 6.95 & Mosaic \\
\hline $30-39$ & 1.12 & 3.05 & 0.83 & 2.28 & 0.56 & 1.74 & $2.28 * *$ & 9.76 & 1.56 * & 4.75 & Scattered \\
\hline $40-49$ & 1.05 & 2.85 & 1.28 & 3.61 & 0.31 & 1.36 & $3.11^{* * *}$ & 22.49 & $1.69 *$ & 5.40 & Scattered \\
\hline \multicolumn{12}{|l|}{ Education status } \\
\hline High school & $-1.14^{*}$ & 0.32 & -0.70 & 0.50 & -0.74 & 0.48 & -1.16 & 0.31 & -0.49 & 0.61 & Connected \\
\hline Marital status & & & & & & & & & & & \\
\hline Unmarried & $1.18^{* *}$ & 3.26 & 0.49 & 1.64 & 0.69 & 1.99 & 0.26 & 1.29 & 0.28 & 1.33 & Linear \\
\hline 1 person & 0.38 & 1.46 & $1.56^{* *}$ & 4.74 & 0.19 & 1.21 & $1.99 * *$ & 7.30 & 0.88 & 2.40 & Scattered \\
\hline 2 persons & 1.08 & 2.94 & $1.39 * *$ & 4.00 & 0.86 & 2.36 & $2.04^{* * *}$ & 7.67 & 1.07 & 2.91 & Scattered \\
\hline 3 persons & 0.54 & 1.72 & 0.78 & 2.17 & 0.24 & 1.27 & $1.25 *$ & 3.48 & 0.82 & 2.27 & Scattered \\
\hline 4 persons & 0.06 & 1.06 & 0.86 & 2.37 & 0.74 & 2.10 & 1.58 * & 4.85 & 0.42 & 1.52 & Scattered \\
\hline \multicolumn{12}{|l|}{ Number of elderly people } \\
\hline 1 person or less & -0.39 & 0.67 & $-0.98^{*}$ & 0.38 & -0.50 & 0.61 & -0.66 & 0.52 & -0.18 & 0.83 & Connected \\
\hline \multicolumn{12}{|l|}{ Health status } \\
\hline Relatively good & -1.95 & 0.14 & $-1.68^{*}$ & 0.19 & $-1.78 *$ & 0.17 & -0.59 & 0.56 & $-2.96^{* *}$ & 0.05 & Connected \\
\hline Commonly & -0.53 & 0.59 & 0.10 & 1.10 & -0.35 & 0.70 & -1.00 & 0.37 & $-0.93 *$ & 0.40 & Branch \\
\hline \multicolumn{12}{|l|}{ Residence in Beijing } \\
\hline Within 1 years & -0.46 & 0.63 & -0.62 & 0.54 & 0.52 & 1.69 & $-2.01 *$ & 0.13 & -0.88 & 0.42 & Chain \\
\hline 5 to 10 years & -0.86 & 0.42 & $-1.35 *$ & 0.26 & 0.27 & 1.31 & $-1.52 *$ & 0.22 & -0.84 & 0.43 & Chain \\
\hline 10 to 15 years & -0.19 & 0.83 & $1.19 *$ & 3.27 & 0.55 & 1.73 & 0.82 & 2.28 & 0.74 & 2.10 & Branch \\
\hline \multicolumn{12}{|c|}{ Months of residence in Beijing every year } \\
\hline Within 3 months & 0.59 & 1.80 & 0.36 & 1.43 & 0.88 & 2.40 & $2.05 *$ & 7.76 & 1.47 & 4.34 & Scattered \\
\hline \multicolumn{12}{|l|}{ Per capita monthly income } \\
\hline$¥ 4000$ and below & $1.74^{* *}$ & 5.67 & 1.19 & 3.28 & -0.06 & 0.94 & 1.27 & 3.55 & $2.47^{* * *}$ & 11.86 & Mosaic \\
\hline$¥ 4001-¥ 8000$ & 1.22 & 3.40 & 1.33 * & 3.79 & 0.20 & 1.22 & $1.82 * *$ & 6.20 & $2.02 * *$ & 7.53 & Mosaic \\
\hline$¥ 12,001-¥ 16,000$ & 1.83 ** & 6.22 & 1.00 & 2.72 & 0.59 & 1.81 & $1.78^{*}$ & 5.94 & $2.28 * *$ & 9.79 & Mosaic \\
\hline$¥ 16,001-¥ 20,000$ & 0.41 & 1.50 & 1.53 & 4.64 & 0.95 & 2.58 & $1.59 *$ & 4.88 & $2.46^{* *}$ & 11.65 & Mosaic \\
\hline \multicolumn{12}{|l|}{ Residential area } \\
\hline 5th-6th Ring Rd & 0.00 & 1.00 & 0.20 & 1.22 & -0.77 & 0.46 & $2.13 *$ & 8.43 & 0.47 & 1.60 & Scattered \\
\hline $\mathrm{C}$ & -1.65 & - & -1.81 & - & -0.04 & - & $-5.41^{* *}$ & - & $-3.52 *$ & - & - \\
\hline
\end{tabular}

Note: Due to the limited layout, this table only presents significant results of parameter estimates. ${ }^{* * *}, * *$, and ${ }^{*}$ represent significant levels of $1 \%, 5 \%$, and $10 \%$, respectively. 
Younger citizens had a wider understanding of urban forests. They could generate mosaics the different areas in urban forest in their memory, and draw mosaic-like cognitive maps [43]. In comparison, the memories of older citizens were weaker, but they visited the urban forests more frequently. Their perceptions of urban forests were more concentrated and focused. Therefore, the image perception of older citizens was embodied in scattered cognitive map.

The connected cognitive map drawn by citizens with a secondary education level (i.e., high school diploma) was a relatively high-level cognitive map, demonstrating that the perceptions of spatial images in urban forest by citizens was closely related to their educational level [48]. Respondents with fewer elderly family members had less responsibility in caring for the elderly, and more leisure time for activities in urban forest areas. Regarding urban forest regional activities, this segment of citizens has a deep perception of the spatial image of an urban forest, drawing higher levels of connected cognitive maps.

Unmarried citizens drew linear cognitive maps, which was the map type drawn by most respondents. These maps only contained the main roads related to urban forests, representing a shallow type of spatial image perception. The citizens with better physical health had more energy and physical strength, and were generally more active in urban forest areas. Their hand-drawn cognitive maps had a connected and branched style, demonstrating sufficiently deep memories of certain urban forest elements. They could connect these elements through the main traffic roads, to form a generally branch map.

Citizens who had lived in Beijing for 10-15 years could draw a branch cognitive map, whereas those who had lived in Beijing for less than 10 years could only draw a chain cognitive map to obtain a chain cognitive space. Most of the citizens who lived in Beijing for less than three months each year, and who lived between the 5th and 6th Rings, were considered the floating population in Beijing. Their perceptions of the spatial image of an urban forest were relatively concentrated, only drawing the most impressive elements of urban forests as scattered cognitive maps.

The key elements of cognitive maps can be classified based on image elements according to the classification method of Lynch (1960), these maps are primarily and intuitively assessed from the richness of certain elements, including landmarks, paths, nodes, regions, and boundaries [42]. Landmarks in the current study were reference points provided to the citizens in urban forests, including famous scenic spots and other elements that can be perceived and, potentially, make an impression on citizens. Because this study focused on typical forest parks, suburban parks, and urban parks, which have clearly delineated administrative boundaries, this study separated the landmarks into internal landmarks and external landmarks for research. This study primarily focused on urban forest areas, in which the respondents entered from the actual level and psychological level. The node was where citizens enter areas, with the function of connecting, such as a squares and parking lots. The boundary was the area or location between two regions, such as entrances and exits. The path was the road provided by urban forests, connecting different scenic spots or locations, such as greenways, footpaths, and ropeways. This information was used to generate frequency distribution statistics of the cognitive maps of citizens based on familiar factors. Figure 4 shows the distribution of familiarity factors in cognitive maps. Overall, citizens were more familiar with the perception of interior landmarks and regional elements of forest parks, the nodes and boundaries of suburban parks, and external landmarks and paths of urban parks.

By integrating familiar elements in the cognitive maps of Xiangshan Park, Summer Palace, and Yuyuantan Park, this study evaluated the familiarity of citizens with the spatial image perception of a forest park, suburban, park and urban park, respectively. Through classifying the six dimensions of cognitive map image elements (i.e., internal landmarks, external landmarks, paths, nodes, regions, and boundaries), the most prominent elements of urban forest types were identified (Figure 5). 


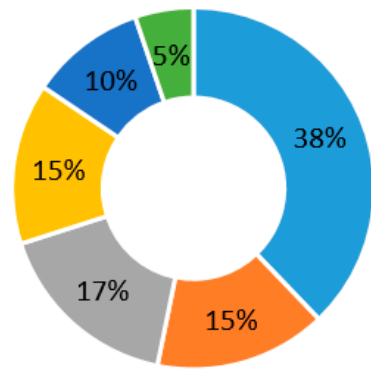

(Forest Park)

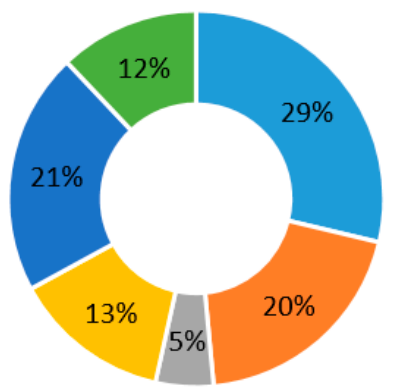

(Suburban Park)

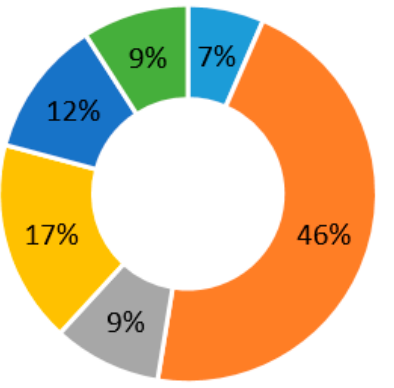

(Urban Park)
- Internal Landmarks

- External Landmarks

a Regions

$=$ Roads

- Nodes

- Boundaries

Figure 4. Frequency distribution of familiar units in the cognition maps of different kinds of urban forests.

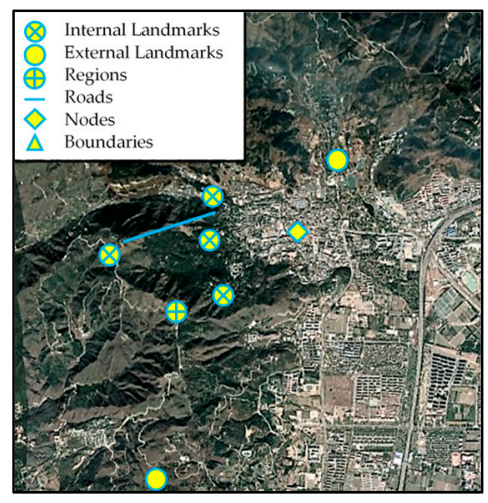

(Forest Park)

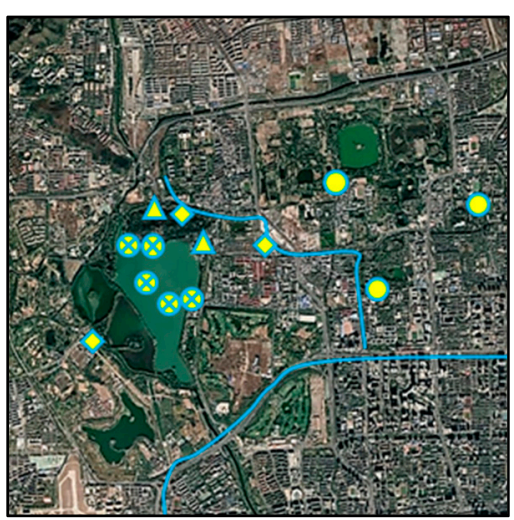

(Suburban Park)

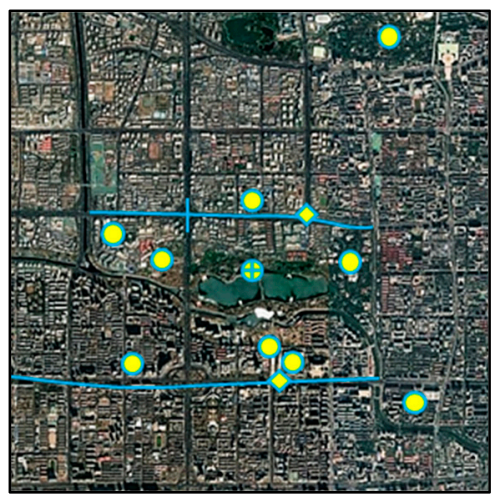

(Urban Park)

Figure 5. Examples of familiar units in the cognition maps of three types of urban forests.

Xiangshan Park represented a forest park, with the prominent internal landmarks being the famous scenic spots. These elements are rooted in the development process of forest parks, and are unique to forest parks, including famous mountains, ancient temples. The geographical locations of forest parks determine the characteristics of their internal markers and corresponding external markers. For instance, Beijing Botanical Garden and Badachu Park are adjacent to Xiangshan Park, reflecting the characteristics of forest parks, namely the remote geographical location, remarkable natural form, and high greening coverage. Because of the unique natural and cultural landscape of forest parks, people place more focus on the main scenic spots due to the time and effort required to access them. Communication through the media and public opinion about famous scenic spots cause citizens to form an a priori sense of familiarity. In contrast, forest parks had a lower level of cognitive familiarity, in terms of paths, nodes, and boundaries. This is because citizens are not focused on the degree of neatness and artificial planning of forest parks. Citizens primarily focused on the ecological environment and landscape services provided by forest parks. Therefore, the elements of paths, nodes, and boundaries tend to be overlooked in the cognitive maps drawn by citizens.

The Summer Palace represented a suburban park, with unique characteristics, in addition to famous natural and historical landscapes, such as Kunming Lake, Seventeen-Cone Bridge, and the Bronze Bull Sculpture. Suburban parks are located at the junction of forest parks and city parks, connecting urban and rural areas geographically, with intensive transportation networks. When citizens visit suburban parks for sightseeing and recreational activities, they must pass through transportation hubs. Therefore, whether residents are urban or rural, their most familiar and intuitive understanding of suburban parks is focused on nodes and boundaries. Citizens primarily identified elements such as subways, bus hubs, entrances, and exits. Thus, many citizens had a general image perception near the boundary of suburban parks. This feature was unique to suburban parks. This cognitive familiarity of 
citizens reflected the important role of nodes and boundaries when constructing the overall images of urban forests.

Urban parks are located in highly-urbanized areas, extending the many natural functions of forests to urban areas, and bringing socialized service functions and values to citizens. Citizens primarily focused on how urban parks were integrated with the overall urban development. Compared to forest parks and country parks, urban parks have the advantages of population, economy, society, and other resources. Their external landmarks are prominent and diverse, encompassing schools, hospitals, and government agencies, as well as other scenic spots of the city. Citizens have the highest perception of paths in these parks, because of the highly dense urban road network. Citizens and urban roads had the highest frequently of contact, with highly familiar perceptions. Finally, although the citizens were familiar with the nodes of urban parks, their familiarity is still lower than that of the corresponding elements of suburban parks.

\section{Conclusions}

Over the last 40 years of reform and opening up, China's urban economy and society have developed rapidly; however, urbanization has also generated environmental pollution and damaged the ecology. Consequently, urbanization has had a serious negative impact on the health and quality of life of citizens. In recent years, the Chinese government has focused on creating a resource-saving and environment-friendly society, with the awareness and concern of citizens about urban environmental issues also increasing. However, as beneficiaries, the perceptions and understanding of citizens about urban forests is crucial to develop and improve urban forests effectively. This study used three typical urban forest forms (forest parks, suburban parks, and urban parks) to provide a comprehensive insight on the characteristics of how citizens perceive urban forests through spatial image perceptions combined with individual characteristics using the semantic differential method and cognitive map method. This study advanced knowledge on the spatial cognition and familiarity of citizens in different types of urban forests. Compared with other studies based subjective visions, such as image analysis, the conclusions of this study are more abundant and reasonable.

Major differences in the perceptions of color and psychological spatial images of urban forests were documented among citizens. The advantages and disadvantages of various types of urban forests are closely related to their geographical location and corresponding location conditions. Citizens perceived the spatial images in color and psychology of these different parks differently, whereas differences in the perceptions of other aspects were relatively moderate. The most direct perception of spatial images by citizens often tends to be intuitive and superficial. In parallel, different types of urban forests have different characteristics, providing a basis for the future planning and development various types of urban forests. For instance, different types of urban forests could be built according to local conditions. In addition, Wu and Xiao (2010) stated that "the overall design of open space should pay attention to the accessibility, continuity and functionality of space" [49]. Therefore, it is necessary to focus on coordinating and unifying various types of urban forests to ensure an orderly and rational spatial transition, which would contribute to the overall urban forest construction.

The perceptions of spatial images by citizens differed significantly because of their individual characteristics, including gender, educational background, and income level. Thus, Beijing's urban forests should be constructed based on the specific needs of men and women, as well as the needs of citizens with different educational backgrounds and income levels. Therefore, the benefits of different types of urban forests should be promoted to incorporate the needs of different groups of citizens, to optimize the use of all kinds of urban forests by citizens. Yet, the individual characteristics of citizens are also strongly correlated to the perceptual elements of urban forests in terms of space, color, style, and environment. These perceptual elements are the most important components in the perceiving the spatial images of urban forests. Citizens also primarily focus on these elements, and so should be integrated in future processes of constructing and improving urban forests. Of importance, the simple natural form, rich forest landscape, and strong elements of modern construction cannot satisfy the 
needs of citizens. The perception of citizens needs to be improved by combining a variety of sensory effects and integrating nature and modern style.

Regarding the classification and characteristics of cognitive maps, the types of cognitive maps drawn by Beijing citizens of urban forest fell into two main categories: sequential cognitive maps and spatial cognitive maps (53.13\% and $46.88 \%$, respectively). The results of the current study showed that the sequential cognitive map based on road elements and the spatial cognitive map based on regional elements accounted for similar percentages in the perception of spatial images of urban forests by citizens, i.e., the spatial image perception of Beijing citizens on urban forests was relatively balanced. However, these perceptions were generally superficial.

Regarding the factors influencing the structure of cognitive maps, clear differences existed among the three types of urban forest. These differences were reflected in the six types of cognitive maps drawn by citizens. Specifically, younger citizens had a wider understanding of urban forest, while older citizens had a more focused perception. The perceptions of spatial images in urban forests were positively correlated with educational level. Citizens with better physical health and fewer family elders perceived spatial images more deeply. Unmarried citizens also had a deep spatial image perception. The floating population of Beijing had a relatively concentrated spatial image perception of urban forests.

The perception of spatial images in urban forests by citizens was reflected in the elements of the six types of cognitive maps. Out of these, the most prominent internal signs of the forest park were its famous scenic spots and places of interest. These elements are rooted in the development of the forest park, and are unique to it. Citizens were primarily concerned about the ecological environment and natural landscape services provided by the forest park. The most familiar and intuitive perception of citizens on the suburban park was focused on the node and boundary. Many citizens had a general perception of the spatial image of the country park near the boundary. Various external signs of the city park were prominent, with citizens focusing on the social service functions that it provided.

The computational results of this study showed that it is possible to quantitatively analyze the subjective perceptions of spatial images by citizens through combining the semantic differential method and cognitive map method. However, considering that the construction of Beijing's urban environment is constantly changing, the perception of urban spatial images by citizens needs continuous re-evaluation and improvements. In addition, the types of urban forests in Beijing could be further subdivided, with areas of research being expanded or focused accordingly, to obtain more targeted conclusions.

Author Contributions: Conceptualization, Z.Z. and Y.W.; methodology, Z.Z.; software, Z.Z.; validation, J.R., and Z.Z.; formal analysis, Z.Z.; investigation, Z.Z., and J.R.; resources, Y.W.; data curation, Z.Z.; writing-original draft preparation, Z.Z.; writing-review and editing, J.R.; visualization, Z.Z.; supervision, Y.W.; project administration, Y.W.; funding acquisition, Y.W. All authors have read and agreed to the published version of the manuscript.

Funding: This study is financially supported by Beijing Municipal Bureau of Arboriculture.

Conflicts of Interest: The authors declare no conflict of interest. The founding sponsors had no role in the design of the study; in the collection, analyses, or interpretation of data; in the writing of the manuscript, and in the decision to publish the results.

\section{References}

1. Carlson, A. The aesthetic appreciation of environmental architecture under different conceptions of environment. J. Aesthet. Educ. 2006, 40, 77-88. [CrossRef]

2. Ren, H.; Zhai, F.; Zhao, H. Exploration of spatial planning and design in urban park activities based on citizen participation. J. Chin. Urban For. 2018, 16, 39-43.

3. Xi, X.; Fan, L.; Deng, X. An analysis of the results of the public survey on China's public environmental awareness. China Soft Sci. 1998, 9, 24-30.

4. Dwyer, J.F.; Nowak, D.J.; Watson, G.W. Future directions for urban forestry research in the United States. J. Arboric. 2002, 5, 231-236. 
5. Gorman, J. Residents' opinions on the value of street trees depending on tree allocation. J. Arboric. 2004, 30, $36-43$.

6. Sipilä, M.; Tyrväinen, L. Evaluation of collaborative urban forest planning in Helsinki, Finland. Urban For. Urban Green. 2005, 4, 1-12. [CrossRef]

7. Vries, S.D.; Verheij, R.A.; Groenewegen, P.P.; Spreeuwenberg, P. Natural environments-healthy environments? An exploratory analysis of the relationship between greenspace and health. Environ. Plan. A 2003, 35, 1717-1731. [CrossRef]

8. Chen, J.; Wang, X.; Yang, X.; Zhu, J.; Shen, Q. Building up a green Beijing- an ambitious urban forestry program. For. Chron. 2013, 89, 127-128. [CrossRef]

9. Clark, K.H.; Nicholas, K.A. Introducing urban food forestry: A multifunctional approach to increase food security and provide ecosystem services. Landsc. Ecol. 2013, 28, 1649-1669. [CrossRef]

10. Wang, X.; Wang, C.; Ding, C. Study on Spatial Layout Planning of Forest City Construction in Yangzhou City. J. Jiangsu For. Sci. Technol. 2010, 37, 38-41.

11. Ruan, W.; Yao, Q.; Shen, L. Discussion on the overall planning of Simen forest town construction in Yuyao City. Acta Agric. Shanghai 2013, 29, 138-141.

12. Bodin, M.; Hartig, T. Does the outdoor environment matter for psychological restoration gained through running? Psychol. Sport Exerc. 2003, 4, 141-153. [CrossRef]

13. Pretty, J.; Peacock, J.; Sellens, M.; Griffin, M. The mental and physical health outcomes of green exercise. Int. J. Environ. Health Res. 2005, 15, 319-337. [CrossRef]

14. Han, M.; Li, Z. Ecological Benefits Evaluation of Urban Forest and Its Models. World For. Res. 2011, $24,42-46$.

15. Steinberg, T. American Green-the Obsessive Quest for the Perfect Lawn; W. W. Norton \& Company: New York, NY, USA, 2006.

16. Gobster, P.H.; Nassauer, J.I.; Daniel, T.C.; Fry, G. The shared landscape: What does aesthetics have to do with ecology? Landsc. Ecol. 2007, 22, 959-972. [CrossRef]

17. Brody, S.D.; Highfield, W.; Alston, L. Does location matter? Environ. Behav. 2004, 36, 229-250. [CrossRef]

18. Nash, R. Wilderness and the American Mind; Yale University Press: New Haven, CT, USA, 2001; pp. 13-19.

19. Li, X. Geographical Study of Human Settlement Environment; Science Press: Beijing, China, 2015; pp. $106-113$.

20. Zhuang, W. SD Method Related to Evaluation of Architectural Space Objectives. J. Tsinghua Univ. 1996, 36, $42-47$.

21. Llinares, C.; Page, A. Application of product differential semantics to quantify purchaser perceptions in housing assessment. Build. Environ. 2007, 42, 2488-2497. [CrossRef]

22. Hansmann, R.; Hug, S.M.; Seeland, K. Restoration and stress relief through physical activities in forests and parks. Urban For. Urban Green. 2007, 6, 213-225. [CrossRef]

23. Huang, Y. The Concept of "Organic Renovation" in the Plan and Reconstruction of Urban Historic Park-On the Base of the Appraisal of Lhasa Zongjiaolukang Park. J. Nanjing For. Univ. 2009, 33, 135-138.

24. Yu, S.; Yuan, S. A Study on the Integrated Perception of Park Landscape Based on SD Method: A Case Study of Fuzhou. Tour. Sci. 2012, 26, 85-94.

25. Zhu, J.; Zhang, T.; Chen, Y. Application of SD method to quality assessment of forest recreation space in Beijing. Guangdong Agric. Sci. 2012, 39, 224-227.

26. Jiang, K. The Research on the Evaluation System of Residential Landscape on SD Method; HeFei University of Technology: Hefei, China, 2012.

27. Fakeye, P.C.; Crompton, J.L. Image differences between prospective, first-time, and repeat visitors to the lower Rio Grande Valley. J. Travel Res. 1991, 30, 10-16. [CrossRef]

28. Golledge, R.; Stimpson, R.J. Spatial Behavior: A Geographic Perspective; The Guilford Press: New York, NY, USA, 1997.

29. Choi, W.M.; Chan, A.; Wu, J. A qualitative and quantitative assessment of Hong Kong's image as a tourist destination. Tour. Manag. 1999, 20, 361-365. [CrossRef]

30. Arnberger, A.; Eder, R. The influence of green space on community attachment of urban and suburban residents. Urban For. Urban Green. 2012, 11, 41-49. [CrossRef]

31. Singleton, R.; Straits, B.C. Approaches to Social Research; Oxford University Press: Oxford, UK, 1999; p. 244.

32. Ren, L.; Qiu, Z.; Ding, H.; Yan, J. Research on survey quality: Evaluation of the representativeness of survey responses. Society 2014, 34, 196-214. 
33. Zhang, W.; Liu, W.; Li, Y. Housings' spatial distribution and residents' preference on housing location in Beijing. Geogr. Res. 2003, 22, 751-759.

34. Osgood, C.E.; Suci, G.J.; Tannenbaum, P.H. The Measurement of Meaning; University of Illinois Press: Urbana, IL, USA, 1957; Volume 7, pp. 503-504.

35. Wang, D.; Zhang, Y. Study of Street Space Perception in Shanghai Based on Semantic Differential Method. J. Tongji Univ. 2011, 39, 1000-1006.

36. Zhao, M.; Shao, L.; Lin, Y. Perceptional Differences of Urban Space between Visitors and Local Residents: A Case Study of West Towns in Nanhai, Guangdong Province. Tour. Sci. 2013, 27, 46-58.

37. Tolman, E.C. Cognitive maps in rats and men. Psychol. Rev. 1948, 55, 189-208. [CrossRef]

38. Gao, J. Spatial Cognition and Cognitive Cartography of Maps. In Papers Collection of the Annual Conference of Cartography in China; Sino Maps Press: Beijing, China, 1992; pp. 56-59.

39. Jiang, Z.; Wu, G.; Bai, G. A Spatial Analysis of the Image of Tourist Destiantions-A Case Study on Ancient Water Towns in Southern Yangtze River. Tour. Trib. 2004, 19, 32-36.

40. Feng, J. Spatial Cognition and the Image Space of Beijing's Residents. Sci. Geogr. Sin. 2005, 25, 142-154.

41. Jiang, Z.; Zhang, J.; Han, G.; Cao, J. A Study Review of Cognitive Maps of Tourists. Tour. Trib. 2009, $24,77-85$.

42. Lynch, K. The Image of the City; The MIT Press: Cambridge, MA, USA, 1960.

43. Appleyard, D. Styles and methods of structuring a city. Environ. Behav. 1970, 2, 100-117. [CrossRef]

44. Hart, R.A.; Moore, G.T. The Development of Spatial Cognition: A Review. In Image and Environment; Downs, R.M., Stea, D., Eds.; Aldine: Chicago, IL, USA, 1973; pp. 246-288.

45. Siegel, A.W.; White, S.H. The development of spatial representations of large-scale environments. In Advances in Child Development and Behavior; Reese, H.W., Ed.; Academic: New York, NY, USA, 1975.

46. Allen, G.L. The organization of route knowledge. New Dir. Child Adolesc. Dev. 1982, 15, 31-39. [CrossRef]

47. Xue, L.; Shen, S.; Liu, Y. The Comparison between Two Cognitive Map Externalization Methods: A Case Study of Beijing. Acta Sci. Nat. Univ. Pekin. 2007, 44, 413-420.

48. Zhang, C.; Bai, K.; Ma, Y. The research on inbound tourists' cognition sequence for spatial image of urban destinations in Xi'an. Geogr. Res. 2014, 33, 1315-1334.

49. Wu, Y.; Xiao, B. Landscape Design and Integration of City Public Open Space. J. Northwest For. Univ. 2010, 25, 188-191.

(C) 2020 by the authors. Licensee MDPI, Basel, Switzerland. This article is an open access article distributed under the terms and conditions of the Creative Commons Attribution (CC BY) license (http://creativecommons.org/licenses/by/4.0/). 